\title{
Дайковый пояс на севере Западно-Арктической платформы по геофизическим данным
}

\author{
Шипилов Э.В. ${ }^{1}$, Шкарубо С.И. ${ }^{2}$ \\ ${ }^{1}$ Полярный геофизический институт, Мурманск, shipilov@pgi.ru \\ ${ }^{2}$ Морская арктическая геологоразведочная экспедиция, Мурманск, sergeysh@mage.ru
}

\begin{abstract}
Аннотация. Совместный анализ магнитометрических и сейсморазведочных данных позволил высказать соображения о продолжении полосы даек архипелага Земля Франца-Иосифа через бассейн Святой Анны в пределы Северо-Карского шельфа. Этот дайковый пояс имеет дискордантные соотношения со структурнотектоническим планом Свальбардской плиты, трога Святой Анны и Карской (Северо-Карской) плиты. Проявления дайкового магматизма проиллюстрировано на сейсмических разрезах пересекающих положительные магнитные аномалии как регионального, так и локального уровня. Резко наложенный характер раннемелового дайкового пояса по отношению к основным тектоническим элементам севера Западно-Арктической платформы указывает на отсутствие связей пояса с развитием тех или иных ее впадин и прогибов. Это приводит к выводу о том, что образование рассматриваемого дайкового пояса обусловлено более глобальными геодинамическими причинами по нашим представлениям связанными со становлением структурной системы Арктического бассейна.
\end{abstract}

Ключевые слова: Земля Франца-Иосифа, Свальбардская плита, трог Святой Анны, Карская плита, Северная Земля, магнитные аномалии, сейсмический разрез, дайковый пояс, Арктический бассейн.

\section{Dyke belt in the north of the West Arctic platform according to geophysical data}

\author{
Shipilov E.V. ${ }^{1}$, Shkarubo S.I. ${ }^{2}$ \\ ${ }^{1}$ Polar Geophysical Institute, Murmansk, shipilov@pgi.ru \\ ${ }^{2}$ Marine Arctic geological exploration expedition, Murmansk,sergeysh@mage.ru
}

\begin{abstract}
A joint analysis of magnetometric and seismic data made it possible to formulate considerations about the continuation of the Franz Josef Land archipelago dike strip through the St. Anna Basin into the North Kara shelf. This dike belt has discordant relationships with the structural-tectonic plan of the Svalbard Plate, St. Anne's Trough, and the Kara (North Kara) Plate. Manifestations of dike magmatism are illustrated in seismic sections crossing positive magnetic anomalies at both regional and local levels. The sharply superimposed character of the Early Cretaceous dike belt in relation to the main tectonic elements of the north of the West Arctic Platform indicates the absence of links between the belt and the development of certain depressions and troughs. This leads to the conclusion that the formation of the considered dike belt is due to more global geodynamic reasons, in our opinion, associated with the formation of the structural system of the Arctic basin.
\end{abstract}

Keywords: Franz Josef Land, Svalbard plate, St. Anna's trough, Kara plate, Severnaya Zemlya, magnetic anomalies, seismic section, dyke belt, Arctic basin.

\section{Введение}

Наибольший объем информации о дайковом поясе получен при изучении арх. Земля ФранцаИосифа (ЗФИ) и его шельфового обрамления. Архипелаг и прилегающий шельф в магнитном поле отчетливо представлен полосовыми аномалиями С3-ЮВ простирания (рис. 1). Эти аномалии однозначно совпадают с дайками различной мощности и протяженности и подводящими магматическими каналами, адаптированными к разломам соответствующей ориентировки (Шипилов и др., 2018). Результаты бурения трех параметрических скважин на островах и изучения обнажений показывают наличие в разрезах многочисленных тел базальтоидов в виде силлов, даек, штоков, покровов, а также вулканогенно-осадочных комплексов (Кораго и др., 2018; Шипилов, Карякин, 2011; Шипилов, Лобковский, 2016). Полученные нами ${ }^{40} \mathrm{Ar} /{ }^{39} \mathrm{Ar}$ - методом определения абсолютного возраста нескольких даек в центре арх. ЗФИ (о. Хейса) показали значения в диапазоне 138 - 133 - 125 млн. лет (валанжин - баррем) (Шипилов, Карякин, 2011). На юго-восточном шельфовом обрамлении ар- 

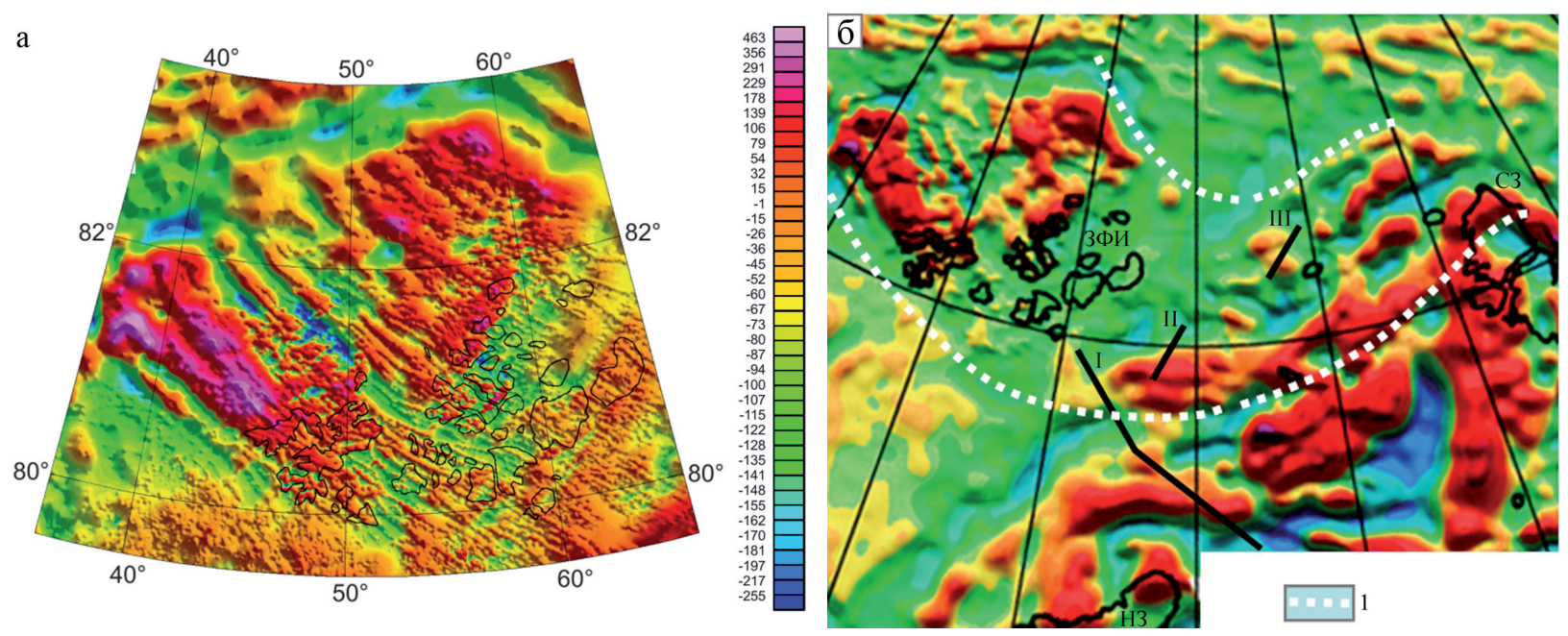

Рис. 1. а - карта магнитных аномалий арх. Земля Франца-Иосифа и прилегающего шельфа и шкала интенсивности аномалий, нТл (ПМГРЭ); б - положение линий сейсмических разрезов (I, II, III) на уменьшенной генерализованной карте магнитных аномалий. 1 - пунктирные линии - контуры пояса даек арх. Земля ФранцаИосифа (ЗФИ) и его возможное продолжение в пределах континентальной окраины Карского моря. С3 - Северная Земля, НЗ - Новая Земля.

Fig. 1. a - map of magnetic anomalies of arch. Franz Josef Land and adjacent shelf and anomaly intensity scale, nT (PMGRE); $b$ - the position of the lines of seismic sections (I, II, III) on a reduced generalized map of magnetic anomalies. 1 - dashed lines - contours of the dike belt of arch. Franz Josef Land (ЗФИ) and its possible continuation within the continental margin of the Kara Sea. C3 - Severnaya Zemlya, H3 - Novaya Zemlya.

хипелага, в 45 км к востоку от о-ва Сальм (по $80^{\circ}$ с. ш.) зафиксирована и опробована дайка с возрастом 120-121.9 4.8 млн. лет (Пискарев и др., 2009), что дает основание считать эти оценки характерными в целом для всего пояса. Все эти данные в совокупности с морскими геофизическими исследованиями, проведенными в последние годы в северной части Баренцево-Карской континентальной окраины, позволили в общих чертах наметить продолжение раннемелового пояса даек со Свальбардской плиты далее на восток в пределы Карской. Трассирование этого пояса базировалось на прослеживании согласованных положительных аномалий магнитного поля.

Материалы региональной сети сейсморазведки МОВ ОГТ (МАГЭ), линии разрезов которой пересекают эти аномалии, в ряде случаев (в зависимости от параметров объекта и разрешающей способности сейсмики) подтверждают наличие даек. Об этом свидетельствуют и пики на графиках кривых аномального магнитного поля, размещенные над сейсмическими разрезами. Однако, следует заметить, что определенный «сглаживающий» эффект в уровни положительных аномалий вносят многочисленные пластовые тела силлов, особенно распространенные на шельфовом обрамлении ЗФИ, но не всегда выраженные на сейсмических разрезах.

Северная часть Карского моря все еще остается слабо изученным в геолого-геофизическом отношении регионом, в том числе и в плане проявлений позднемезозойского магматизма. Отметим, что на островах арх. Северная Земля не исключен меловой возраст субширотно ориентированных даек габбро-долеритов, занимающих, как отмечается (Кузьмин и др., 2010) «резко секущее по отношению к основным геологическим структурам положение». Но конкретные определения возраста этих образований не приводятся.

\section{Интерпретация сейсмических разрезов}

На рисунке $2 a$ в волновой картине иллюстрируемого разреза по интервалам колонн нарушенной сейсмической записи довольно отчетливо выделяются две группы объектов локализованных в пределах контуров закартированных положительных аномалий магнитного поля.

Первая группа, судя по всему, обусловленная телами даек, зафиксированная в северо-западной части разреза, расположена в непосредственной близости от ЗФИ и сопровождается горизонтами 

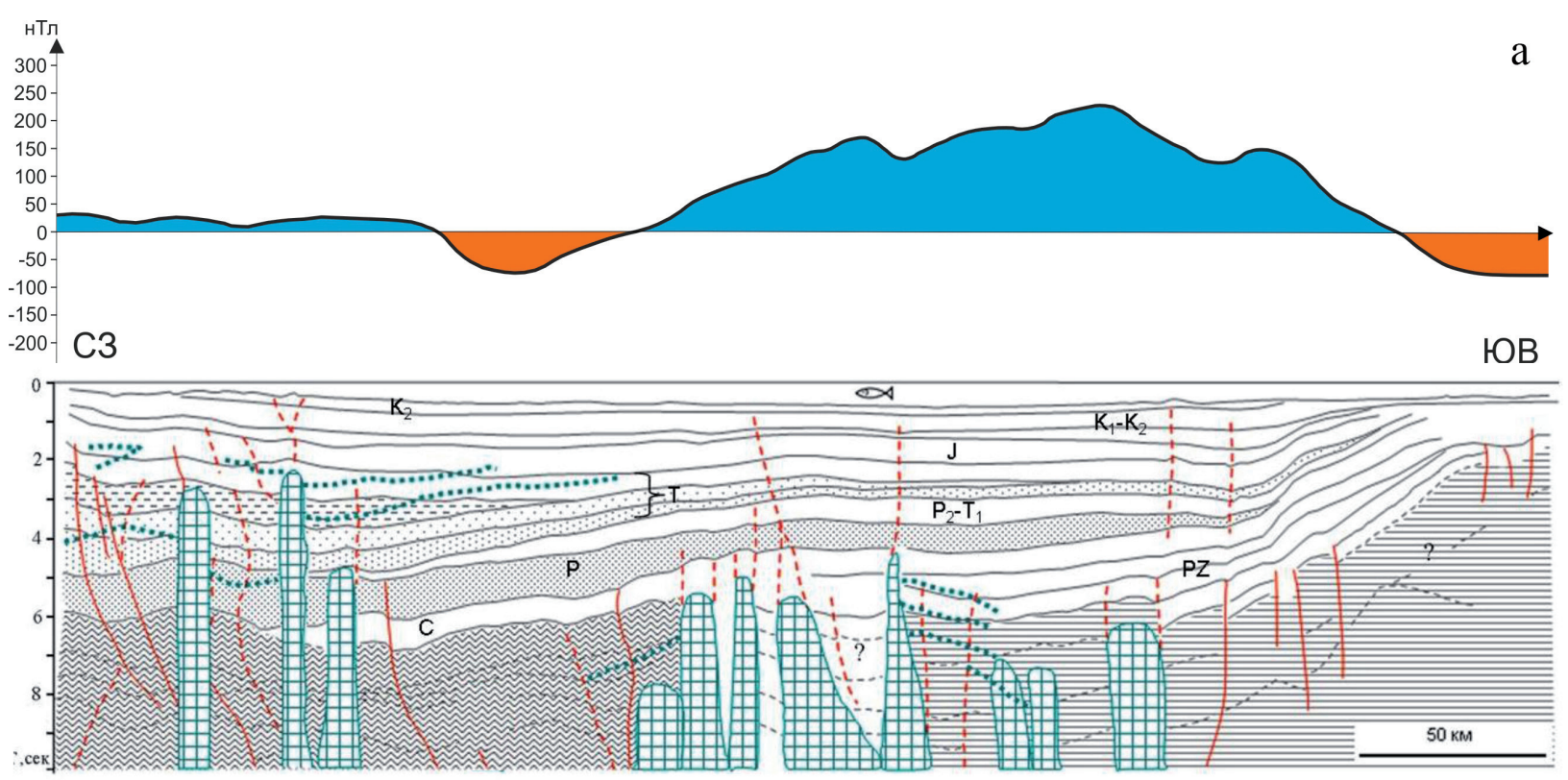

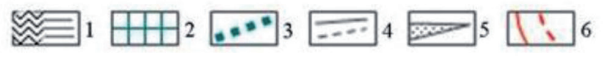
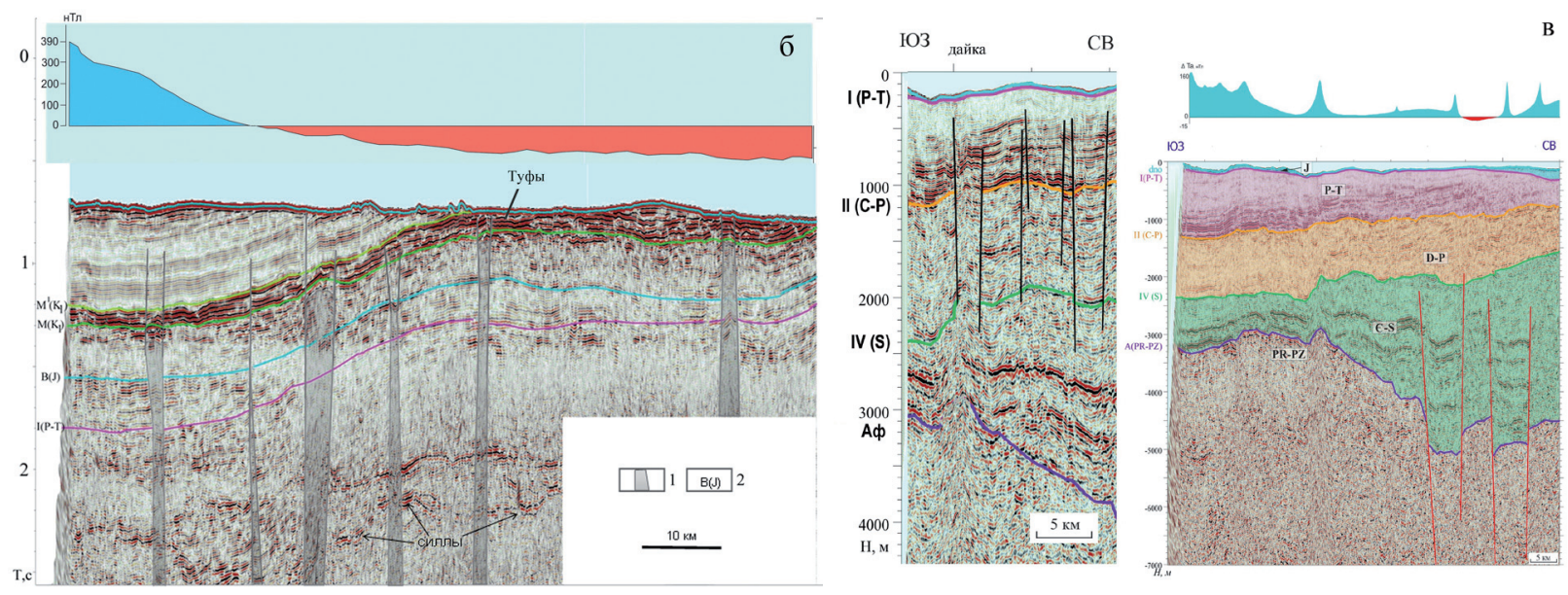

Рис. 2. Интерпретированные разрезы.

$\mathrm{a}-$ фрагмент сейсмогеологического разреза ВК-111 по линии 4 (положение на рис. 1 - линия I) через желоб Святой Анны. 1 - акустический фундамент, 2 - интервалы разреза с нарушенной волновой картиной и деформациями вмещающих пород, обусловленными внедрением даек и их комплексов (?), 3 - силлы, 4 - основные и прочие отражающие горизонты (границы сейсмокомплексов), 5 - сейсмокомплексы выклинивания, 6 - разломы и зоны трещиноватости.

б - фрагмент временного сейсмического разреза AN 1603 по линии II (положение на рис. 1) в западной прибортовой зоне трога Святой Анны иллюстрирующий проявления интрузивного магматизма в виде даек (в т.ч. не проявленных в магнитном поле в виду малой мощности) и силлов в верхней части осадочного чехла.

1 - интервалы нарушенной сейсмической записи, обусловленной влиянием даек, 2 - сейсмостратиграфическая привязка основных отражающих горизонтов: I(Р-T) - вблизи кровли триаса, В(J) - вблизи кровли юры, $\mathrm{M}(\mathrm{K} 1)$ - в отложениях барремского яруса нижнего мела, $\mathrm{M}^{\prime}(\mathrm{K} 1)$ - в отложениях аптского яруса нижнего мела. в - глубинный сейсмический разрез AN 1636 по линии III (положение рис. 1) на восточном борту желоба Святой Анны (западнее о-ва Ушакова, шельф Карского моря). Слева его увеличенный фрагмент, иллюстрирующий интервал сейсмической записи отражающей дислокационное воздействие внедрения дайки на вмещающие комплексы осадочного чехла. Сейсмостратиграфическая привязка отражающих горизонтов: Аф - акустический фундамент, IV(S) - вблизи кровли силурийских отложений, II(C-P) - кровля карбонатного комплекса каменноугольно-пермского возраста. 
Fig. 2. Interpreted sections.

a - fragment of the seismic-geological section BK-111 along line 4 (position in fig. 1 - line I) through the St. Anna Trough. 1 - acoustic basement, 2 - intervals of the section with a disturbed wave pattern and deformations of host rocks caused by the intrusion of dikes and their complexes (?), 3 - sills, 4 - main and other reflecting horizons (boundaries of seismic complexes), 5 - pinch-out seismic complexes, 6 - faults and fracture zones.

6 - fragment of the time seismic section AN 1603 along line 5 (position in fig. 1) in the western near-belt zone of the St. Anna Trough illustrating the manifestations of intrusive magmatism in the form of dikes (including those not manifested in a magnetic field due to a small thickness) and sills in the upper part of the sedimentary cover.

1 - intervals of the disturbed seismic record caused by the influence of dikes, 2 - seismostratigraphic referencing of the main reflecting horizons: I (P-T) - near the top of the Triassic, B $(\mathrm{J})$ - near the top of the Jurassic, M (K1) - in the deposits of the Barremian stage of the Lower Cretaceous, M '(K1) - in the deposits of the Aptian stage of the Lower Cretaceous. B - deep seismic section AN 1636 along line III (position fig. 1) on the eastern side of the St. Anna Trough (west of Ushakov Island, shelf of the Kara Sea). On the left is an enlarged fragment illustrating the interval of the seismic record reflecting the dislocation effect of the intrusion of the dike on the host complexes of the sedimentary cover. Seismic stratigraphic referencing of reflecting horizons: Aф - acoustic basement, IV (S) - near the top of the Silurian deposits, II (C-P) - the top of the carbonate complex of the Carboniferous-Permian age.

силлов. Над головной оконечностью даек сформированы под воздействием внедрения интрузий антиклинальные формы в перекрывающих отложениях осадочного чехла. При этом последние сопровождаются нарушениями, либо зонами трещиноватости, которые проникают в меловые отложения, отражая, таким образом, разгрузку напряжений.

Вторая группа объектов, отображенная в центральной части разреза, находится за пределами предполагаемого нами мелового пояса и их головные части затрагивают лишь верхнепалеозойские комплексы отложений. Эта группа отличается значительно большей концентрацией объектов и преувеличенными их размерами, а также локализацией вблизи депоцентра бассейна Св. Анны где зафиксирована отрицательная аномалия гравитационного поля в редукции Буге. О масштабах влияния этих «тел» на структуру бассейна можно судить не только по локальным деформациям над их головными частями, но и, в целом, по сформированной над этой группой довольно значительной по размерам антиформы в перекрывающих отложениях. Природа этих образований, учитывая их размеры, остается не ясной, несмотря на то, что они связаны со значительной по масштабам и интенсивности положительной магнитной аномалией. Можно предположить, что они связаны с Р-Т тектономагматическими событиями. К тому же следует учитывать возможное искажение размера этих деформационных колонн в сторону увеличения в связи с тем, что линия разреза пересекает простирание магнитной аномалии под острым углом. Следует также заметить, что зона «внедрения» рассматриваемой группы образований является разделом различных по облику отражений блоков акустического фундамента.

На рисунке 26 сейсмический разрез, в отличие от предыдущего, пересекает продолжающиеся с ЗФИ дайки, судя по структуре магнитного поля, практически ортогонально их простиранию. Отчетливо видно, что головные части даек «упираются» в комплекс отложений, представленный по нашему мнению вулканогенно-осадочными образованиями аптского яруса нижнего мела. Деформированность этих отложений над головами даек свидетельствует о том, что дайки воздействовали на них по образу и подобию поршня, выталкивая кверху по разломам. Следует заметить, что описываемый разрез расположен над крупной и интенсивной положительной аномалией магнитного поля маркирующей южное ограничение пояса даек, и выделенная серия объектов однозначно отражает магматическую природу этой аномалии.

Фрагмент глубинного сейсмического разреза на рисунке 2 в расположен над локализованной положительной магнитной аномалией в пределах Карской плиты западнее о. Ушакова. Зафиксированная в волновой картине наиболее заметная магматическая интрузия как нельзя лучше характеризует весь набор черт свойственный дайкам отображаемым на сейсмических разрезах. Хорошо заметно, что это магматическое тело прорывает акустический фундамент, нарушает прослеживание 
осей синфазности и деформирует примыкающие сейсмические границы в осадочном разрезе. Вместе с тем в рассматриваемом интервале сейсмической записи имеют место «засвеченные» участки, а над головной частью интрузии, ограниченной нарушениями, отмечается облекающий и выпуклый облик перекрывающих горизонтов осадочного чехла. Указанная дайка отчетливо идентифицируется пиком на графике кривой аномального магнитного поля.

На дальнейшее продолжение пояса даек в северной части Карской плиты указывают цепочки положительных магнитных аномалий, которые по мере их прослеживания к северо-востоку начинают изменять свои простирания на субширотные. На границе с котловиной Нансена аномалии, судя по положению их заключительных фрагментов, плавно разворачиваются в юго-восточном направлении, теряют свою выразительность и, по существу, срезаются бортовой зоной океанической впадины. Однако в южном сегменте Евразийского бассейна наблюдаются, видимо, остаточные магнитные аномалии юго-восточной ориентировки. Они сохранились на сильно растянутых блоках континентального фундамента и вступают в диссонанс с линейными магнитными аномалиями, сопровождающими развитие осевого спредингового центра хребта Гаккеля.

\section{Заключение}

Ширина предполагаемого дайкового пояса арх. ЗФИ соответствует ширине этого сводовоблокового поднятия и составляет 400 км, а в пределах Карской плиты испытывает сужение в 1.5 раза. Общая протяженность пояса по дуге составляет порядка 900-1000 км.

Особенностью расположения предполагаемого дайкового пояса является отсутствие соподчиненности в его соотношениях с элементами структурно-тектонического плана как в пределах Свальбардской плиты, так и Карской, включая и трог Св. Анны. При этом при переходе от одной плиты к другой дайковый пояс, как показывают магнитные аномалии, испытывает разворот с юговосточного простирания (дайки ЗФИ) на северо-восточное. Этот дугообразный изгиб пояс претерпевает при пересечении зоны разломов в пограничной структуре трога Св. Анны.

Следует отметить и такую характерную для дайкового пояса особенность как снижение интенсивности связанных с ним аномалий в магнитном поле при прослеживании с запада на восток, что связано с заглублением магнитоактивных тел. Не смотря на мощные эрозионные процессы при кайнозойском аплифте, а также экзарационную деятельность, на ряде островов ЗФИ дайки отчетливо экспонируются на дневной поверхности, а иногда даже в рельефе дна окружающего шельфа. В прогибе Св. Анны и в пределах Карской плиты дайки находятся на глубине соответственно от первых километров до 6-7 километров. Но как показывают результаты геологических съемок, аналогичные по форме проявления интрузии базальтоидов обнаруживаются на о-вах Северной Земли и не исключается их меловой возраст (Кузьмин и др., 2000; Кораго и др., 2018).

Резко наложенный характер раннемелового дайкового пояса по отношению к структурнотектоническому плану севера Западно-Арктической платформы указывает на отсутствие связей пояса с развитием тех или иных ее впадин и прогибов. Это приводит к выводу о том, что образование рассматриваемого дайкового пояса обусловлено более глобальными геодинамическими причинами по нашим представлениям связанными со становлением структурной системы Арктического бассейна. Сопоставляя дайковые пояса Канадского Арктического архипелага, континентальных окраин Баренцево-Карского и, по всей видимости, Восточно-Сибирского региона, достаточно очевидно, что они образуют общий дугообразный контур, обозначивший площадь динамического воздействия мантийного плюма на литосферу Арктики. Со стороны Баренцево-Карской окраины дайковый пояс ограничивает возникновение субсогласных с ним зон разрыва и дальнейшего отчленения сегментов литосферы. С двух других сторон, - Гренландско-Североамериканской и Сибирско-Чукотской, рассматриваемые пояса даек сопрягаются с зонами сдвигов. В конечном итоге это привело к обособлению, на соответствующем этапе геодинамической эволюции, Амеразийской микроплиты и ее перемещению по направлению к тихоокеанской зоне субдукции.

Работа выполнена при финансовой поддержке РФФИ в рамках научного проекта № 18-05-70012 по программе «Ресурсы Арктики». 


\section{Литература}

1. Кораго Е.А., Столбов Н.М., Проскурнин В.Ф. Магматические комплексы островов западного сектора Российской Арктики . СПб. Изд-во: ВНИИОкеангеология. 2018. С. 74-100.

2. Кузьмин В.Г., Авдюничев В.В., Гавриш А.В. и др. Северная Земля. Геологическое строение и минерагения. СПб. Изд-во: ВНИИОкеангеология. 2000. 187 с.

3. Пискарев А.Л., Хойнеман К., Макарьев А.А., Макарьева Е.М., Бахтадзе В., Алексютин М. Магнитные параметры и вариации состава магматических пород архипелага Земля Франца-Иосифа // Физика Земли. 2009. № 2. С. 66-83.

4. Шипилов Э.В., Карякин Ю.В. Баренцевоморская магматическая провинция: геолого-геофизические свидетельства и новые результаты определения 40Ar/39Ar возраста // ДАН. 2011. Т. 439. № 3. С. 376-382. DOI: $10.1134 / \mathrm{S} 1028334 X 11070270$.

5. Шипилов Э.В., Лобковский Л.И. Позднемезозойский плюмовый магматизм Арктического региона: геохронология, фазы и геодинамические обстановки проявления // Арктика: экология и экономика. 2016. № 2 (22). С. 72-81.

6. Шипилов Э.В., Шкарубо С.И., Митяев М.В. Тектоника Земли Франца-Иосифа и прилегающего шельфа // Труды Ферсмановской научной сессии ГИ КНЦ РАН. 2018. № 15. С. 396-400.

DOI: $10.31241 /$ FNS.2018.15.100. 